\title{
Is the 1298A > C polymorphism in the MTHFR gene a risk factor for arterial ischaemic stroke in children? The results of meta-analysis
}

\author{
Beata Sarecka-Hujar ${ }^{1}\left[\right.$ !llona Kopyta ${ }^{2} \cdot$ Michal Skrzypek $^{3}$
}

Received: 6 November 2017 / Accepted: 22 January 2018 / Published online: 2 February 2018

(C) The Author(s) 2018. This article is an open access publication

\begin{abstract}
An elevated level of homocysteine is a risk factor for vascular diseases, brain atrophy and several other disorders. The 1298A $>$ C polymorphism (rs1801131) leads to mildly decreased MTHFR activity. Previously, it was observed that the MTHFR $1298 \mathrm{~A}>\mathrm{C}$ polymorphism in combined analysis with the MTHFR 677C $>\mathrm{T}$ polymorphism increases homocysteine levels. However, conflicting results on its relation to ischaemic stroke in children can be found. We conducted a meta-analysis to analyse possible connections between the MTHFR 1298A >C polymorphism and ischaemic stroke in paediatric patients. We identified available data published before December 2016 using appropriate keywords and searching PubMed as well as the references cited in the found articles. Eight case-control studies were included in the meta-analysis (426 children with stroke and 778 controls). Statistical analyses were made using R and Comprehensive Meta-Analysis softwares to investigate the impact of polymorphism in four models: dominant, recessive, additive and allelic. No publication bias was observed in the meta-analysis. We demonstrated no relationship between the 1298A $>$ C polymorphism and ischaemic stroke in children in the case of recessive, additive and allelic models. However, the results of the dominant model analysis should be treated with caution due to the sensitivity analysis results. After omitting one of the included study, we observed a significant association between the carriers of the MTHFR C allele (cases with AC + CC genotypes) and ischaemic stroke in children (OR 1.35 $95 \%$ CI $1.02-1.79, p=0.035$ in a fixed effects model). In conclusion, the $1298 \mathrm{~A}>\mathrm{C}$ polymorphism in the MTHFR gene is not a risk factor for ischaemic stroke in paediatric patients.
\end{abstract}

Keywords Arterial ischaemic stroke $\cdot$ Children $\cdot$ Gene $\cdot$ MTHFR $\cdot 1298$ A $>$ C polymorphism

\section{Introduction}

Neurologic consequences of arterial ischaemic stroke (AIS) in children or young adults, especially under 45 years of age, are devastating. The most prevalent stroke outcomes are: motor impairment (hemiparesis is observed most

Beata Sarecka-Hujar

bsarecka-hujar@sum.edu.pl

1 Department of Pharmaceutical Technology, School of Pharmacy with the Division of Laboratory Medicine in Sosnowiec, Medical University of Silesia in Katowice, Kasztanowa Str 3, 41-200 Sosnowiec, Poland

2 Department of Paediatric Neurology, School of Medicine in Katowice, Medical University of Silesia in Katowice, Medykow str 16, 40-072 Katowice, Poland

3 Department of Biostatistics, School of Public Health in Bytom, Medical University of Silesia in Katowice, Piekarska str 18, 41-902 Bytom, Poland commonly), speech impairment, intellectual delay, seizures and death $[1,2]$. The problem of these deficits is noteworthy due to their effect on the daily activity of patients. However, it is not possible to find the aetiology of AIS in one-third of young cases under the age of 40 [3]. In children from Saudi Arabia, the aetiological factor of AIS was undetermined in $65 \%$ of cases [4].

It is observed that the level of homocysteine (HCys) plays an important role in the functioning of endothelial cells. An elevated level of HCys is a risk factor for vascular diseases, brain atrophy as well as pregnancy complications, migraine or neuropsychiatric disorders [5-8]. Several common polymorphisms in the genes encoding enzymes involved in homocysteine metabolism are suggested to be associated with the development of AIS, both in adults and children. The gene encoding methylenetetrahydrofolate reductase, located in $1 \mathrm{p} 36.22$, is the most studied. The $677 \mathrm{C}>\mathrm{T}$ polymorphism in the MTHFR gene leads to the decreased activity of the enzyme and elevated 
HCys levels [9]. On the other hand, the 1298A $>\mathrm{C}$ polymorphism (rs1801131) results in mildly decreased MTHFR activity [10].

A previous meta-analysis of available data [11] confirmed the association between the carrier state of the 677T allele in the MTHFR gene and AIS in children. However, the role of another common MTHFR polymorphism, 1298A $>C$ in paediatric stroke, is still uncertain. Conflicting results of the studies on the relationship between the 1298A $>$ C polymorphism and AIS, both in children and adults, can be found [12-17]. Previously, it was observed that the MTHFR $1298 \mathrm{~A}>\mathrm{C}$ polymorphism in combined analysis with the $677 \mathrm{C}>\mathrm{T}$ polymorphism increased homocysteine levels as well as lowered plasma folate levels [18]. However, some studies do not confirm such a relationship [19]. In addition, studies on paediatric cases with AIS are performed on small numbers of patients due to the rarity of AIS in this age group and patients are mostly recruited from one medical centre, which may influence the power of results.

The present study aimed to analyse possible connections between the MTHFR 1298A >C polymorphism and AIS in paediatric patients using a meta-analysis of available data addressing this association in children.

\section{Methods}

We identified available data published before December 2016 on the relationship between the $1298 \mathrm{~A}>\mathrm{C}$ polymorphism in the MTHFR gene and AIS in children and adolescents. Two of the authors searched PubMed twice. The references cited in the found articles were also searched in order to find other published articles on the topic. The language of publication was limited to English. We used the following keywords: "MTHFR polymorphism" or "1298A $>$ C polymorphism", "arterial ischemic stroke" or "ischemic stroke" or "cerebral infarct", "paediatric" or "children". We adopted the following inclusion criteria for the present meta-analysis: (a) case-control study, (b) children (including neonates and adolescents) as the study population, (c) AIS confirmed by magnetic resonance imaging or computed tomography and (d) article in English. The exclusion criteria were as follows: (a) lack of genotype or allele frequencies, (b) study designed as not a case-control study (conference proceedings, review articles, case reports, meta-analyses or animal studies), (c) outcome definition other than AIS, (d) patient groups overlapped in previous publications (when several articles of the same author were available, we included only the most recent one or the article with the largest number of cases). The searching process is shown in Fig. 1.

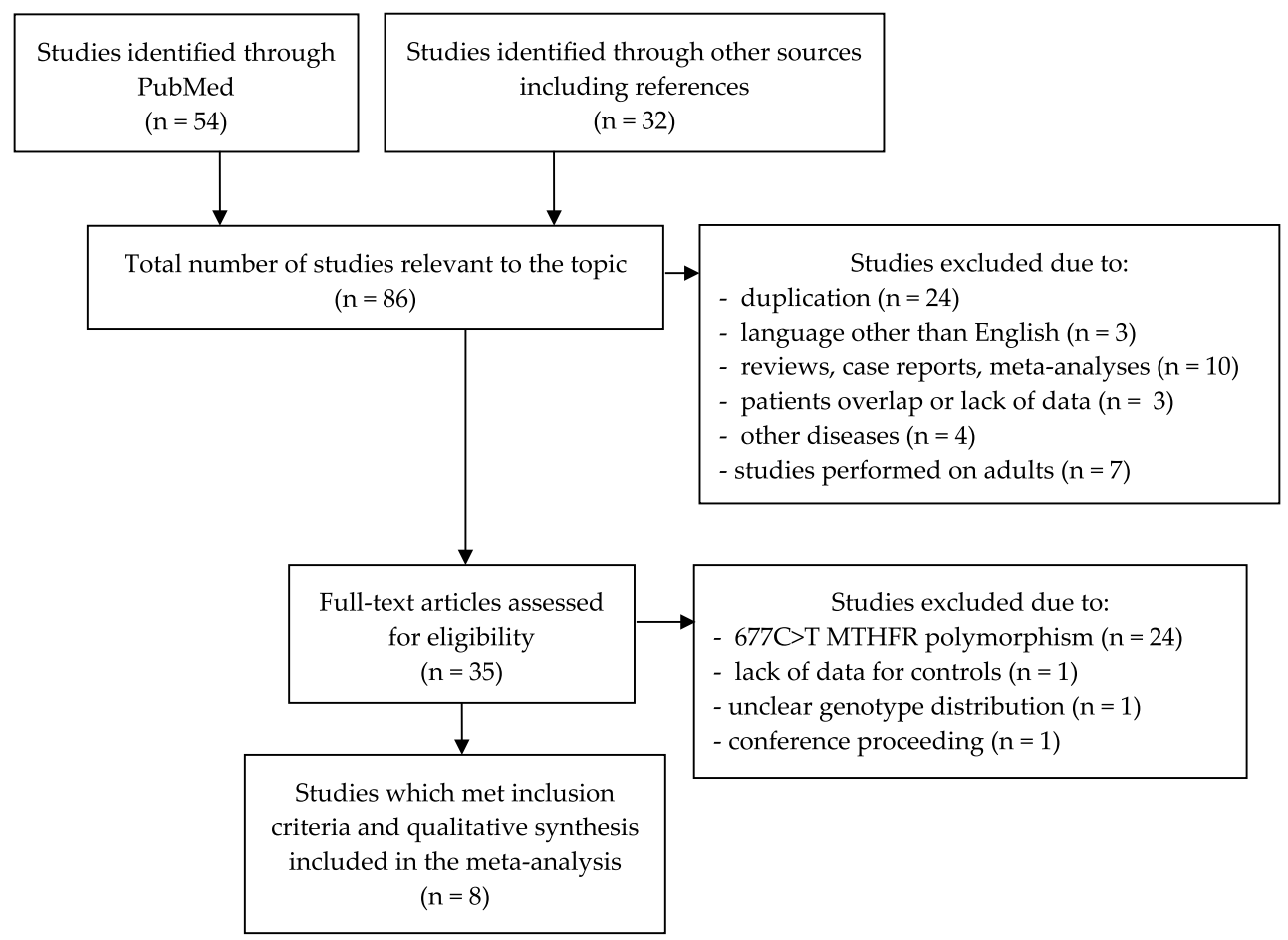

Fig. 1 Flow chart showing process of searching for the articles 
Finally, eight case-control studies were included in the meta-analysis with a total number of 426 paediatric patients with AIS and 778 control subjects [12-14, 20-24].

\section{Data extraction}

Two independent authors extracted the following information from each study according to the inclusion criteria: first author's name, year of publication, population, genotype distribution, sample sizes, age of cases and control subjects and genotyping method. Additionally, Hardy-Weinberg equilibrium (HWE) was calculated according to the frequency of genotypes in controls for each study.

\section{Methodological quality}

Two of the authors assessed independently the methodological quality of the included studies using the Newcastle-Ottawa scale (NOS) for case-control studies [25]. The following three components of each study were analysed: selection (Is the case definition adequate?; Representativeness of the cases; Selection of Controls; Definition of Controls), comparability (Comparability of cases and controls on the basis of the design or analysis) and outcome assessment (Ascertainment of exposure; Same method of ascertainment for cases and controls; Non-Response rate). Quality scores ranged from 0 to 9 . The articles which obtained 5 stars or more were considered as high-quality studies, the others as low-quality studies. For these methodological low-quality reports, we adopted the suggestion of Minelli et al. [26] not to exclude studies that deviated from Hardy-Weinberg equilibrium when no other grounds for doubting the quality of the study were present. Thus we checked the low-quality studies according to the NOS scale for HWE and performed sensitivity analysis by deleting a particular study and reviewing the power of pooled odds ratio (OR). When the pooled OR was stable, we did not ultimately exclude the study from the meta-analysis.

\section{Statistical analyses}

Statistical analyses were performed using R software (version 3.3.1 with "meta" package, version 4.5-0; The R Foundation for Statistical Computing Platform) and CMA software (version 3.3.070, NIH, USA). The pooled OR with the $95 \%$ confidence interval $(\mathrm{CI})$ was calculated to determine the strength of association between the genetic polymorphism and AIS.

We used the random effects method (DerSimonian-Laird) in the case of significant heterogeneity or the fixed effects method (Mantel-Haenszel) in other cases to calculate the pooled OR with the $95 \% \mathrm{CI}$. The assessment of heterogeneity was based on the results of studies. We analysed the association between the MTHFR $1298 \mathrm{~A}>\mathrm{C}$ polymorphism in AIS in four models: dominant (AC + CC vs. AA), recessive ( $\mathrm{CC}$ vs. $\mathrm{AA}+\mathrm{AC})$, additive ( $\mathrm{CC}$ vs. $\mathrm{AA})$ and allelic $(\mathrm{C}$ allele vs. A allele).

Publication bias was analysed using the Egger's regression asymmetry test. The $p$ value below 0.05 was considered statistically significant. The data were put into the statistical software independently by two authors, and the obtained results were the same. Thus, we are sure that the performed statistical analysis was adequate and reliable.

\section{Results}

\section{Study characteristics}

Characteristics of the eight included studies are shown in Table 1. All genotype frequencies in control subjects from the included studies were in agreement with HWE. Caucasians were the most common race. In order to genotype the MTHFR $1298 \mathrm{~A}>\mathrm{C}$ polymorphism, PCR-RFLP analysis was used in four of the studies [12, 13, 20, 21], CVD StripAssays in two studies [14, 22] and Taqman PCR in one study [23]. The genotyping method was not specified in one of the studies [24]. The largest groups of AIS patients were recruited by Balcerzyk et al. [12], Herak et al. [14] and Komitopoulou et al. [22], whereas the fewest patients were recruited by Gelfand et al. [23] and Morita et al. [24]. The largest group of control subjects was analysed in the study by Sirachainan et al. [21] and the lowest one in the study by Biswas et al. [13].

\section{A $>$ C polymorphism and childhood stroke in the dominant model}

We analysed the effect of its association with AIS in four models: dominant, recessive, additive and allelic. As for the dominant model (AC + CC vs. AA), we observed significant heterogeneity between the studies $\left(I^{2}=62.64 \%, p=0.009\right)$. Therefore, the random effects model was used to analyse this combination ( $p=0.395$, OR $1.2195 \%$ CI $0.78-1.89$ ) (Fig. 2a). For the analysed dominant model, the Egger's test did not reveal the presence of publication bias $(R=2.23, p$ $($ two tailed $)=0.907)($ Fig. 3a) .

\section{A $>$ C polymorphism and childhood stroke in the recessive model}

In the recessive model ( $\mathrm{CC}$ vs. $\mathrm{AC}+\mathrm{AA})$, we observed no significant heterogeneity between the studies $\left(I^{2}=13.93 \%\right.$, $p=0.321)$. Therefore, the fixed effects model was used to analyse this combination ( $p=0.777$, OR $1.0695 \% \mathrm{CI}$ 0.69-1.63) (Fig. 2b). For the analysed recessive model, the 


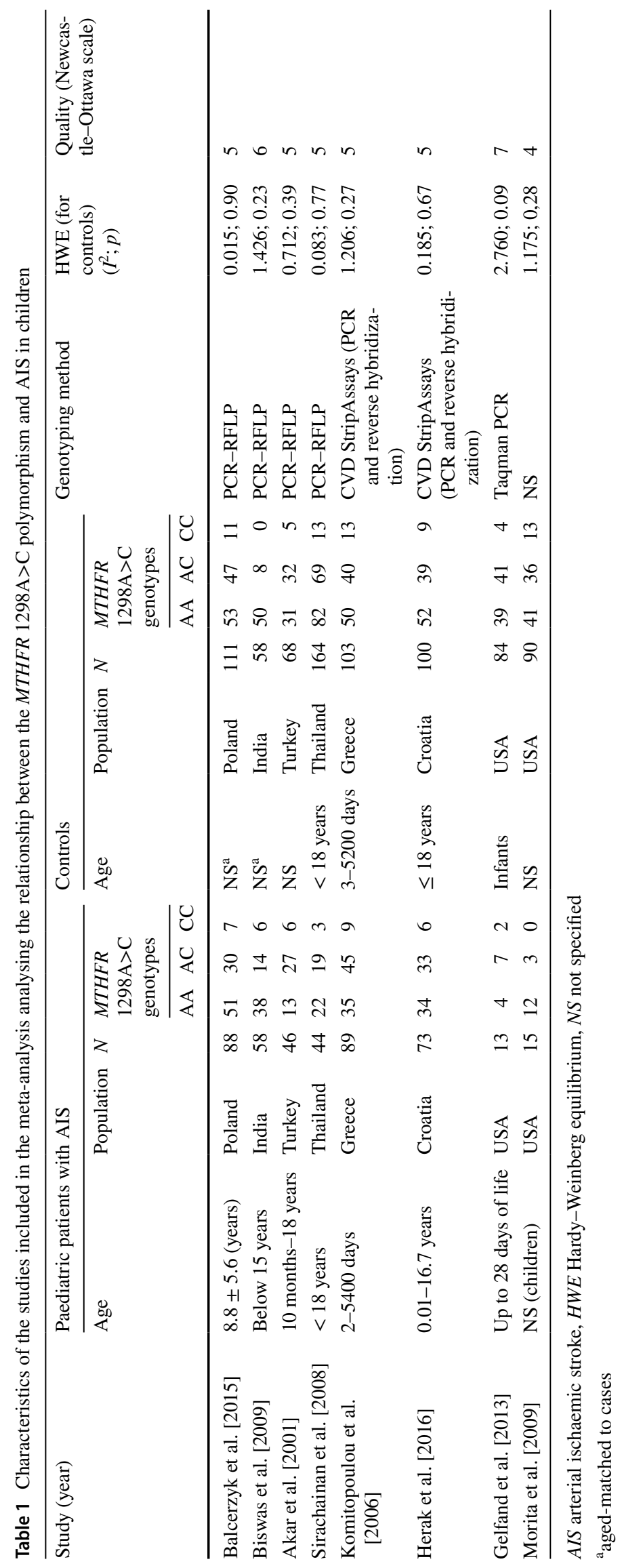


Egger's test did not reveal the presence of publication bias $(R=1.07, p($ two tailed $)=0.299)($ Fig. 3b)

\section{A $>$ C polymorphism and childhood stroke in the additive model}

When analysing the additive model (CC vs. AA), no significant heterogeneity between the studies was also observed $\left(I^{2}=35.33 \%, p=0.146\right)$. In this case, the fixed effects model was again used for analysis ( $p=0.552$, OR $1.1495 \%$ CI 0.74-1.77) (Fig. 2c). In the case of the additive model, the Egger's test did also not reveal the presence of publication bias $(R=1.29, p($ two tailed $)=0.392)($ Fig. $3 \mathrm{c})$.

\section{A >C polymorphism and childhood stroke in the allelic model}

In the allelic model (C allele vs. A allele), significant heterogeneity between the studies was observed $\left(I^{2}=73.91 \%\right.$, $p<0.001)$, so the random effects model was used for calculating the pooled OR ( $p=0.593$, OR $1.1295 \%$ CI $0.74-1.68)$ (Fig. 2d). There was again no publication bias calculated in the Egger's test $(R=2.46, p$ (two tailed $)=0.730)($ Fig. 3d). In addition, we also made a heterozygote comparison (AC vs. AA), but no relationship with AIS was observed.

\section{Sensitivity analysis}

Sensitivity analysis, by sequential exclusion of each study, was included in the meta-analysis to assess the stability of the results. We found no change in the OR value in the case of the recessive, additive and allelic models. However, in the dominant model after omitting the study of Balcerzyk et al. [12], we observed a significant association between the carriers of the MTHFR C allele (cases with AC $+\mathrm{CC}$ genotypes) and AIS in children (OR 1.35 95\% CI 1.02-1.79, $p=0.035$ in the fixed effects model).

\section{Discussion}

The 1298A >C polymorphism in the MTHFR gene leads to a glutamate to alanine substitution within the $\mathrm{C}$-terminal regulatory domain of the MTHF reductase and to reduced enzyme activity. In turn, the $677 \mathrm{C}>\mathrm{T}$ polymorphism concerns the regions encoding the $\mathrm{N}$-terminal catalytic domain of the protein, which corresponds to a greater reduction in the enzyme activity [10]. Data of Castro et al. [27] showed that the $1298 \mathrm{CC}$ as well as $677 \mathrm{TT}$ homozygotes might be potential risk factors for disease states associated with DNA hypomethylation status. Reduced MTHFR activity is related to an increased level of homocysteine which may affect the reduction in DNA methylation and hence be the real cause of cardiovascular diseases [28].

Our meta-analysis, based on a sizeable group of children suffering from AIS and healthy age-matched controls, demonstrated that the 1298A $>$ C polymorphism in the MTHFR gene is not related to paediatric ischaemic stroke in the following models: recessive, additive and allelic. The analysis performed on the dominant model also showed lack of association, but we observed some instability of the results during the sensitivity analysis, and thus the data must be treated with some caution. An earlier meta-analysis including 2361 adult patients with AIS demonstrated that the $1298 \mathrm{~A}>\mathrm{C}$ polymorphism is related to the disease and the strongest association was observed in the case of the additive model [29]. With regard to ethnicity, the authors found an especially strong association in Asians. Similarly, the metaanalysis by Lv et al. [30] showed the strongest relationship between the 1298A $>$ C polymorphism and AIS in the case of the additive model when the Asian subgroup was analysed. However, the authors analysed studies in paediatric and adult patients jointly.

During the searching process, we also took into consideration a study performed in 33 paediatric patients with AIS from Canada, in which the authors found an association between the 1298A $>$ C polymorphism and stroke [31]. However, we have some doubts about the genotype distribution calculated according to the frequencies presented in the paper, so finally this study was excluded. In another study analysing the MTHFR 1298A >C polymorphism in AIS in the group of paediatric patients from the USA, no genotype distribution of the 1298A $>C$ polymorphism was found [32]. We contacted the authors and got some lacking information about this distribution in the case of AIS patients but not in controls. Thus, this study was also excluded from the final analysis.

Available data indicate that AIS is more common in boys [33]. There are some data showing that the $677 \mathrm{C}>\mathrm{T}$ polymorphism in the MTHFR gene may be related to an especially high risk of AIS in boys in Polish population in comparison with girls [34]. In contrast, higher, although not significant, prevalence of the 677T allele was observed in girls with migraine (with aura or without aura) when compared to boys [35]. Unfortunately, none of the studies included to the present meta-analysis show full data of genotype distribution; thus, we were not able to analyse sex subgroups to observe whether a similar relationship concerns the 1298A $>$ C polymorphism. The study by Herak et al. [14] showed no relationship between the MTHFR 1298A >C polymorphism and AIS when considered alone. However, some specific combinations of MTHFR 1298 genotypes with the Factor V Leiden, MTHFR $677 \mathrm{C}>\mathrm{T}$ polymorphism and FV HR2 polymorphism were observed. The authors noticed that the presence of the 1298AC genotype in the carriers of 
A Study

Balcerzyk et al. (2015) Biswas et al. (2009) Akar et al. (2001)

Sirachainan et al. (2008)

Komitopoulou et al. (2006)

Herak et al. (2016)

Gelfand et al. (2013)

Morita et al. (2009)

Fixed effect model

Random effects model

Heterogeneity: 1 -squared $=62.6 \%$, tau-squared $=0.2404, p=0.0090$

Experimental Control Events Total Events Total

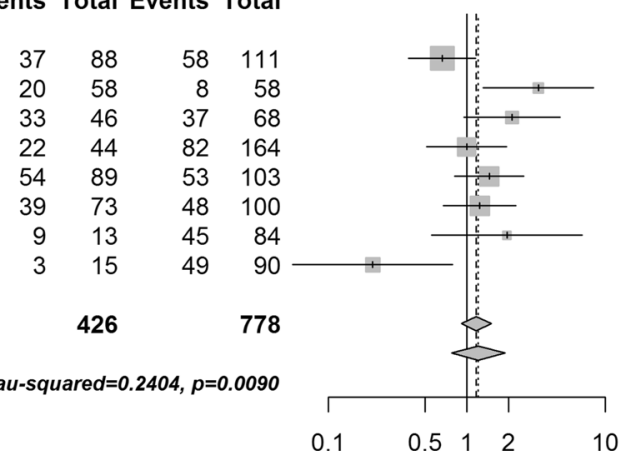

B

Study

Balcerzyk et al. (2015)

Biswas et al. (2009)

Akar et al. (2001)

Sirachainan et al. (2008)

Komitopoulou et al. (2006)

Herak et al. (2016)

Gelfand et al. (2013)

Morita et al. (2009)

Experimental

Control

Events Total Events Total

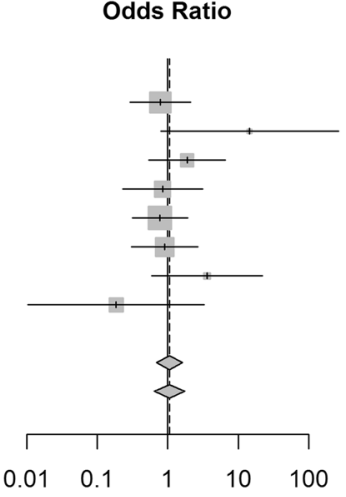

$0.79 \quad[0.29 ; 2.12] \quad 22.0 \% \quad 20.0 \%$

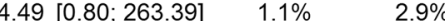

$1.89[0.54 ; 6.60] \quad 8.6 \% \quad 13.7 \%$

$0.85 \quad[0.23 ; 3.12] \quad 12.6 \% \quad 12.8 \%$

$0.78 \quad[0.32 ; 1.92] \quad 26.6 \% \quad 23.1 \%$

$0.91 \quad[0.31 ; 2.67] \quad 17.1 \% \quad 17.5 \%$

$3.64[0.59 ; 22.23] \quad 2.2 \% \quad 7.1 \%$

$0.19[0.01 ; 3.28] \quad 9.6 \% \quad 3.0 \%$

$1.06[0.69 ; 1.63] \quad 100 \% \quad 100 \%$

Random effects mode

Heterogeneity: I-squared $=13.9 \%$, tau-squared $=0.0733, p=0.321$

$1.06[0.64 ; 1.76] \quad--100 \%$

\section{C}

Study

Balcerzyk et al. (2015)

Biswas et al. (2009)

Akar et al. (2001)

Sirachainan et al. (2008)

Komitopoulou et al. (2006)

Herak et al. (2016)

Gelfand et al. (2013)

Morita et al. (2009)

Fixed effect model

Random effects model

Heterogeneity: $I$-squared $=35.3 \%$, tau-squared $=0.2712, p=0.1464$
Experimental Contro

Events Total Events Total

$\begin{array}{lr}7 & 58 \\ 6 & 44 \\ 6 & 19 \\ 3 & 25 \\ 9 & 44 \\ 6 & 40 \\ 2 & 6 \\ 0 & 12\end{array}$

248

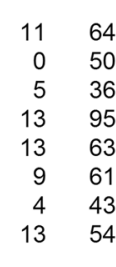

466 4

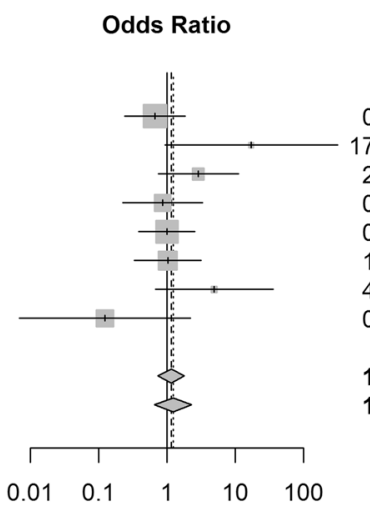

OR $\quad 95 \%-C l$ W(fixed) W(random)

$0.66 \quad[0.24 ; 1.84] \quad 24.9 \% \quad 18.9 \%$

$\begin{array}{lll}17.05[0.93 ; 312.03] & 1.1 \% & 4.1 \%\end{array}$

$2.86[0.74 ; 11.06] \quad 6.4 \% \quad 13.7 \%$

$0.86 \quad[0.23 ; 3.29] \quad 12.9 \% \quad 13.9 \%$

$0.99 \quad[0.38 ; 2.57] \quad 23.0 \% \quad 20.2 \%$

$1.02 \quad[0.33 ; 3.12] \quad 16.4 \% \quad 17.1 \%$

$4.88 \quad[0.67 ; 35.48] \quad 1.8 \% \quad 7.9 \%$

$0.12[0.01 ; 2.22] \quad 13.4 \% \quad 4.2 \%$

$\begin{array}{lrrrr}1.14 & {[0.74 ;} & 1.77] & 100 \% & - \\ 1.22 & {[0.65 ;} & 2.29] & -- & 100 \%\end{array}$
D

Study

Balcerzyk et al. (2015)

Biswas et al. (2009)

Akar et al. (2001)

Sirachainan et al. (2008)

Komitopoulou et al. (2006)

Herak et al. (2016)

Gelfand et al. (2013)

Morita et al. (2009)

Fixed effect model

Random effects model

Heterogeneity: I-squared $=73.9 \%$, tau-squared $=0.2377, p=0.0004$

\section{Experimental Control}

Events Total Events Total

$\begin{array}{rr}44 & 17 \\ 28 & 116 \\ 39 & 9 \\ 25 & 88 \\ 63 & 178 \\ 45 & 14 \\ 11 & 2 \\ 3 & 3\end{array}$

852

69222

8116

$42 \quad 136$

$95 \quad 328$

63206

75200

$49 \quad 168$

62180
1556

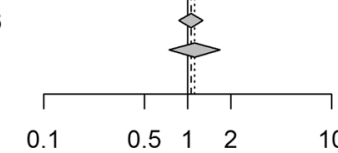

OR

\section{5\%-Cl W(fixed) W(random)}

$0.74[0.47 ; 1.15] \quad 22.3 \% \quad 15.0 \%$

$4.30[1.86 ; 9.90] \quad 3.0 \% \quad 10.3 \%$

$1.65[0.95 ; 2.86] \quad 9.5 \% \quad 13.7 \%$

$0.97[0.58 \cdot 1.64] \quad 14.0 \% \quad 14.0 \%$

$1.24[0.81 ; 1.91] \quad 18.4 \% \quad 15.2 \%$

$0.74[0.47 ; 1.17] \quad 21.3 \% \quad 14.9 \%$

$1.78[0.76 ; 4.15] \quad 3.7 \% \quad 10.2 \%$

$0.21[0.06 ; 0.72] \quad 7.8 \% \quad 6.8 \%$

$1.05[0.87 ; 1.28] \quad 100 \%$

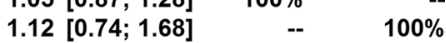


4Fig. 2 Forest plots of association between the 1298A>C polymorphism and arterial ischaemic stroke in children in four statistical models: dominant (a), recessive (b), additive (c) and allelic (d)

Factor V Leiden mutation extremely increased the risk of perinatal stroke (OR 16.5) [14]. This finding supports the assumption that the association analysis of a single gene in a particular disease is insufficient. Several polymorphisms with specific gene-gene interactions should be analysed in case-control studies to draw meaningful conclusions. However, most case-control studies focus on the analysis of a single genetic polymorphism. Thus, in a meta-analysis it is not possible to perform analyses of specific interactions between genes, since it would require very precise data from each included study. It is also very important to know the other coexisting factors (clinical, biochemical and environmental) which may increase the impact of genes on the disease aetiology. Many researchers have raised the issue that the association between two or more genetic risk factors or the association between genes and clinical risk factors may have greater impact on paediatric stroke than a single genetic polymorphism [36, 37]. Previously, in the study by Lanthier et al. [38], children with AIS and multiple risk factors were at greater risk of recurrent stroke than children with one risk factor. One of the studies included in the meta-analysis analysed the transmission of the $1298 \mathrm{C}$ allele from parents to affected children [12]. This issue is important since young adults with parental history of coronary heart disease (CHD) are more at risk of cerebrovascular diseases compared to controls without parental history of CHD [39].

The study by Giusti et al. [40] was conducted on a large population of adults with AIS $(n=501)$ and control subjects $(n=1211)$ and analysed 58 polymorphisms in 17 genes involved in the metabolism of methionine. The association of a single polymorphism with AIS as well as the association between haplotypes and AIS and possible effects of a haplotype combination between the genes were studied. The authors observed that the $677 \mathrm{C}>\mathrm{T}$ and $1298 \mathrm{~A}>\mathrm{C}$ polymorphisms in the MTHFR gene analysed separately have no impact on the risk of ischaemic stroke in the analysed group of adults, whereas the $677 \mathrm{C}>\mathrm{T}$ polymorphism was significantly related to increased levels of homocysteine. There
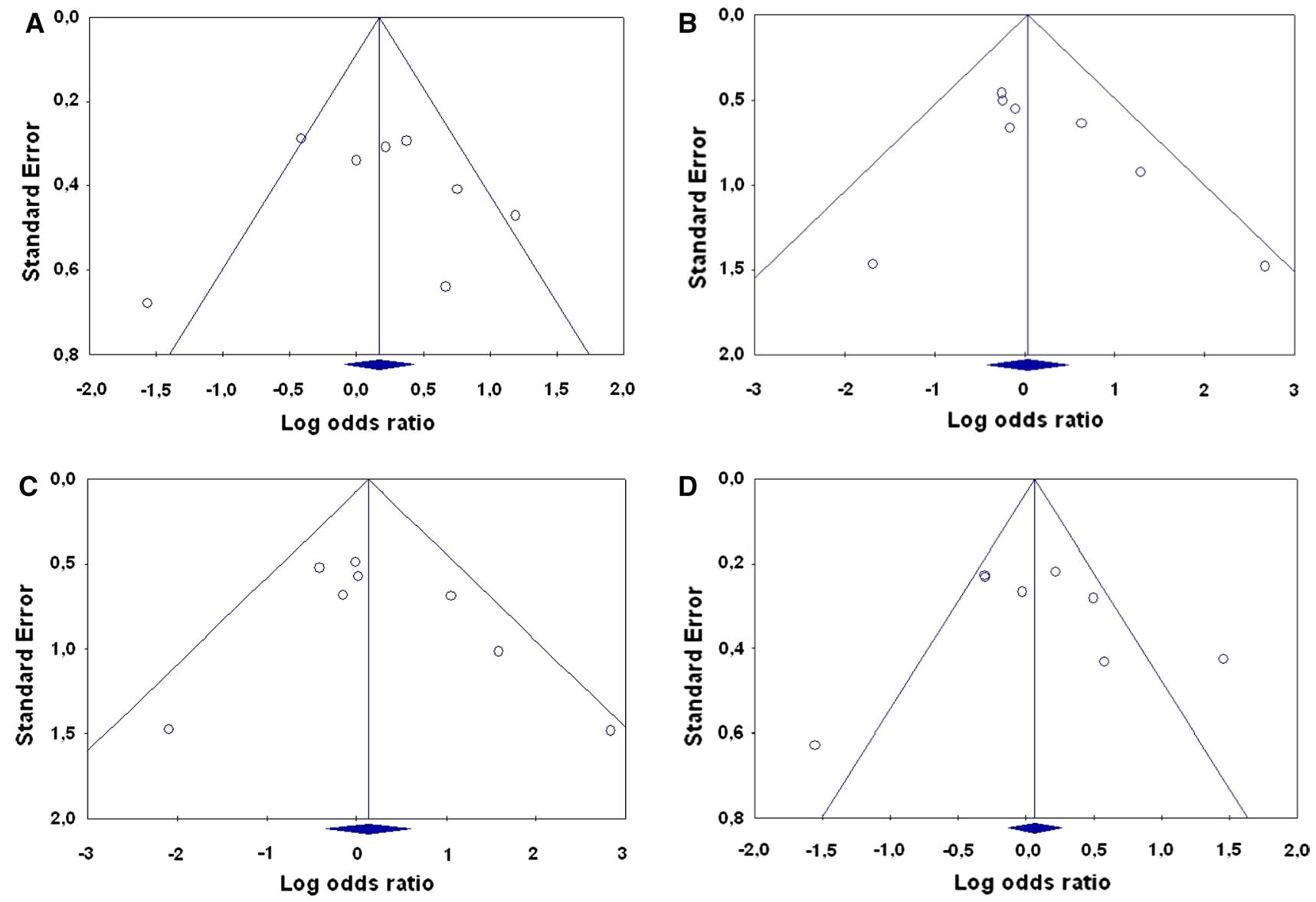

Fig. 3 Funnel plots of the 1298A $>$ C polymorphism in the MTHFR gene in the studies included in the present meta-analysis. a dominant model; b recessive model; $\mathbf{c}$ additive model; and $\mathbf{d}$ allelic model 
were also no associations between the MTHFR haplotypes and stroke [40].

We are aware of some limitations of the present metaanalysis. First of all, there is no homocysteine level analysis since previously it was hypothesized that the presence of MTHFR polymorphisms without elevated levels of homocysteine had no influence on paediatric stroke [41]. Second, there is great variation in the number of recruited paediatric patients in each study (from several patients to a few dozen). A small number of examined patients in a single study is due to the rarity of AIS (the prevalence of AIS in children is estimated at about three cases per year per 100000 children). Moreover, there is probably some selection bias between the studies since the recruited patients were of different ethnic origin and with possible genetic differences.

Analysis of homocysteine levels in correlation with the MTHFR 1298A >C polymorphism would give some important results since it has been proven that hyperhomocysteinemia is an established risk factor for premature cardiovascular diseases caused by endothelial dysfunction [42]. Homocysteine levels can be reduced from 25 to $30 \%$ using folic acid, and supplementation with vitamin B12 provides an additional 7\% reduction [43]. Arpino et al. [44] suggested that early folate supplementation before and during pregnancy could reduce the risk of brain damage due to foetal/perinatal stroke. For practical reasons, establishing homocysteine levels in paediatric patients with the $1298 \mathrm{~A}>\mathrm{C}$ polymorphism and administration of folic acid and cobalamin could also prevent some cardiovascular events in the future [45].

In conclusion, the $1298 \mathrm{~A}>\mathrm{C}$ polymorphism in the MTHFR gene is not related to paediatric arterial ischaemic stroke.

\section{Compliance with ethical standards}

Conflict of interest The authors declare no conflict of interest.

Ethical approval Not required since previously published data were analysed.

Informed consent No patient was recruited to the present study.

Open Access This article is distributed under the terms of the Creative Commons Attribution 4.0 International License (http://creativeco mmons.org/licenses/by/4.0/), which permits unrestricted use, distribution, and reproduction in any medium, provided you give appropriate credit to the original author(s) and the source, provide a link to the Creative Commons license, and indicate if changes were made.

\section{References}

1. Lo WD, Kumar R. Arterial ischemic stroke in children and young adults. Continuum (Minneap Minn). 2017;23:158-80.
2. Greenham M, Anderson V, Mackay MT. Improving cognitive outcomes for pediatric stroke. Curr Opin Neurol. 2017. https://doi. org/10.1097/WCO.0000000000000422.

3. Dragoni F, Chiarotti F, Rosano G, Simioni P, Tormene D, Mazzucconi MG, Cafolla A, Avvisati G. Thrombophilic screening in young patients ( $<40$ years) with idiopathic ischemic stroke: a controlled study. Thromb Res. 2011;127:85-90.

4. Al-Sulaiman A, Bademosi O, Ismail H, Magboll G. Stroke in saudi children. J Child Neurol. 1999;14:295-8.

5. Homocysteine Studies Collaboration. Homocysteine and risk of ischemic heart disease and stroke: a meta-analysis. JAMA. 2002;288:2015-22.

6. Fernández-Rodríguez C, González-Reimers E, Quintero-Platt G, de la Vega-Prieto MJ, Pérez-Hernández O, Martín-González C, Espelosín-Ortega E, Romero-Acevedo L, Santolaria-Fernández F. Homocysteine, liver function derangement and brain atrophy in alcoholics. Alcohol Alcohol. 2016;51:691-7.

7. Marum L, Verma M, Jinsiwale N. Homocysteine as predictive marker for pregnancy-induced hypertension-A comparative study of homocysteine levels in normal versus patients of PIH and its complications. J Obstet Gynaecol India. 2016;66:167-71.

8. Szczygioł D, Motta E, Gołba A, Stęposz A, Witecka J, Dębski M, Błaszkiewicz D, Sieron A. Frequency of the C677T variant of the methylenetetrahydrofolate reductase (MTHFR) gene in patients with migraine with or without aura - a preliminary report. Neurol Neurochir Pol. 2012;46:443-9.

9. Frosst P, Blom HJ, Milos R, Goyette P, Sheppard CA, Matthews RG, Boers GJ, den Heijer M, Kluijtmans LA, van den Heuvel LP, Rozen R. A candidate genetic risk factor for vascular disease: a common mutation in methylenetetrahydrofolate reductase. Nat Genet. 1995;10:111-3.

10. Weisberg IS, Jacques PF, Selhub J, Bostom AG, Chen Z, Curtis Ellison R, Eckfeldt JH, Rozen R. The 1298A >C polymorphism in methylenetetrahydrofolate reductase (MTHFR): in vitro expression and association with homocysteine. Atherosclerosis. 2001;156:409-15.

11. Sarecka-Hujar B, Kopyta I, Pienczk-Reclawowicz K, Reclawowicz D, Emich-Widera E, Pilarska E. The TT genotype of methylenetetrahydrofolate reductase $677 \mathrm{C}>\mathrm{T}$ polymorphism increases the susceptibility to pediatric ischemic stroke: metaanalysis of the 822 cases and 1552 controls. Mol Biol Rep. 2012;39:7957-63.

12. Balcerzyk A, Niemiec P, Kopyta I, Emich-Widera E, Pilarska E, Pienczk-Ręcławowicz K, Kaciński M, Wendorff J, Żak I. Methylenetetrahydrofolate reductase gene A1298C polymorphism in pediatric stroke-case-control and family-based study. J Stroke Cerebrovasc Dis. 2015;24:61-5.

13. Biswas A, Tiwari AK, Ranjan R, Meena A, Akhter MS, Yadav BK, Behari M, Saxena R. Prothrombotic polymorphisms, mutations, and their association with pediatric non-cardioembolic stroke in Asian-Indian patients. Ann Hematol. 2009;88:473-8.

14. Herak DC, Krleza JL, Radic Antolic M, Horvat I, Djuranovic V, Zrinski Topic R, Zadro R. Association of polymorphisms in coagulation factor genes and enzymes of homocysteine metabolism with arterial ischemic stroke in children. Clin Appl Thromb/ Hemost. 2016. https://doi.org/10.1177/1076029616672584.

15. Sazci A, Ergul E, Tuncer N, Akpinar G, Kara I. Methylenetetrahydrofolate reductase gene polymorphisms are associated with ischemic and hemorrhagic stroke: dual effect of MTHFR polymorphisms C677T and A1298C. Brain Res Bull. 2006;71:45-50.

16. Fekih-Mrissa N, Mrad M, Klai S, Mansour M, Nsiri B, Gritli N, Mrissa R. Methylenetetrahydrofolate reductase (C677T and A1298C) polymorphisms, hyperhomocysteinemia, and ischemic stroke in Tunisian patients. J Stroke Cerebrovasc Dis. 2013;22:465-9. 
17. Dikmen M, Ozbabalik D, Gunes HV, Degirmenci I, Bal C, Ozdemir G, Basaran A. Acute stroke in relation to homocysteine and methylenetetrahydrofolate reductase gene polymorphisms. Acta Neurol Scand. 2006;113:307-14.

18. Barbosa PR, Stabler SP, Machado AL, Braga RC, Hirata RD, Hirata MH, Sampaio-Neto LF, Allen RH, Guerra-Shinohara EM. Association between decreased vitamin levels and MTHFR, MTR and MTRR gene polymorphisms as determinants for elevated total homocysteine concentrations in pregnant women. Eur J Clin Nutr. 2008;62:1010-21.

19. Friso S, Girelli D, Trabetti E, Stranieri C, Olivieri O, Tinazzi E, Martinelli N, Faccini G, Pignatti PF, Corrocher R. A1298C methylenetetrahydrofolate reductase mutation and coronary artery disease: relationships with C677T polymorphism and homocysteine/folate metabolism. Clin Exp Med. 2002;2:7-12.

20. Akar N, Akar E, Ozel D, Deda G, Sipahi T. Common mutations at the homocysteine metabolism pathway and pediatric stroke. Thromb Res. 2001;102:115-20.

21. Sirachainan N, Sasanakul W, Visudtibhan A, Tapanapruksakul P, Charoenkwan P, Kadegasem P, Udomsubpayakul U, Chuansumrit A. The effect of polymorphisms of MTHFR C677T, A1298C, MS A2756G and CBS 844ins68 bp on plasma total homocysteine level and the risk of ischemic stroke in Thai children. Thromb Res. 2008;122:33-7.

22. Komitopoulou A, Platokouki H, Kapsimali Z, Pergantou H, Adamtziki E, Aronis S. Mutations and polymorphisms in genes affecting hemostasis proteins and homocysteine metabolism in children with arterial ischemic stroke. Cerebrovasc Dis. 2006;22:13-20.

23. Gelfand AA, Croen LA, Torres AR, Wu YW. Genetic risk factors for perinatal arterial ischemic stroke. Pediatr Neurol. 2013;48:36-41.

24. Morita DC, Donaldson A, Butterfield RJ, Benedict SL, Bale JF Jr. Methylenetetrahydrofolate reductase gene polymorphism and childhood stroke. Pediatr Neurol. 2009;41:247-9.

25. Wells GA, Shea B, O'Connell D, Peterson J, Welch V, Losos M, Tugwell P. The Newcastle-Ottawa Scale (NOS) for assessing the quality of nonrandomised studies in meta-analyses. Available: http://www.ohri.ca/programs/clinical_epidemiology/oxford.asp. Assessed 5 Dec 52016.

26. Minelli C, Thompson JR, Abrams KR, Thakkinstian A, Attia J. How should we use information about HWE in the meta-analyses of genetic association studies? Int J Epidemiol. 2008;37:136-46.

27. Castro R, Rivera I, Ravasco P, Camilo ME, Jakobs C, Blom HJ, de Almeida IT. 5,10-methylenetetrahydrofolate reductase (MTHFR) $677 \mathrm{C}->\mathrm{T}$ and $1298 \mathrm{~A}->\mathrm{C}$ mutations are associated with DNA hypomethylation. J Med Genet. 2004;41:454-8.

28. Cacciapuoti F. Hyper-homocysteinemia: a novel risk factor or a powerful marker for cardiovascular diseases? Pathogenetic and therapeutical uncertainties. J Thromb Thromb. 2011;32:82-8.

29. Zhang MJ, Hu ZC, Yin YW, Li BH, Liu Y, Liao SQ, Gao CY, Li JC, Zhang LL. A meta-analysis of the relationship between MTHFR gene A1298C polymorphism and the risk of adult stroke. Cerebrovasc Dis. 2014;38:425-32.

30. Lv Q, Lu J, Wu W, Sun H, Zhang J. Association of the methylenetetrahydrofolate reductase gene A1298C polymorphism with stroke risk based on a meta-analysis. Genet Mol Res. 2013;12:6882-94.
31. Rook JL, Nugent DJ, Young G. Pediatric stroke and methylenetetrahydrofolate reductase polymorphisms: an examination of C677T and A1298C mutations. J Pediatr Hematol Oncol. 2005;27:590-3.

32. Joachim E, Goldenberg NA, Bernard TJ, Armstrong-Wells J, Stabler S, Manco-Johnson MJ. The methylenetetrahydrofolate reductase polymorphism (MTHFR c.677C $>$ T) and elevated plasma homocysteine levels in a U.S. pediatric population with incident thromboembolism. Thromb Res. 2013;132:170-4.

33. de Veber G. Stroke and the child's brain: an overview of epidemiology, syndromes and risk factors. Curr Opin Neurol. 2002; 15:133-8.

34. Zak I, Sarecka-Hujar B, Kopyta I, Emich-Widera E, Marszal E, Wendorff J, Jachowicz-Jeszka J. The T allele of the $677 \mathrm{C}>\mathrm{T}$ polymorphism of methylenetetrahydrofolate reductase gene is associated with an increased risk of ischemic stroke in Polish children. J Child Neurol. 2009;24:1262-7.

35. Lorenz A-L, Kahre T, Mihailov E, Nikopensius T, Lotman E-M, Metspalu A, Kolk A. Are methylenetetrahydrofolate reductase (MTHFR) gene polymorphisms C677T and A1298C associated with higher risk of pediatric migraine in boys and girls? J Biomed Sci Eng. 2014;7:464-72.

36. Torres VM, Saddi VA. Systematic review: hereditary thrombophilia associated to pediatric strokes and cerebral palsy. J Pediatr (Rio J). 2015;91:22-9.

37. Zadro R, Herak DC. Inherited prothrombotic risk factors in children with first ischemic stroke. Biochem Med (Zagreb). 2012;22:298-310

38. Lanthier S, Carmant L, David M, Larbrisseau A, de Veber G. Stroke in children: the coexistence of multiple risk factors predicts poor outcome. Neurology. 2000;54:371-8.

39. Vulic D, Loncar S, Ostojic M, Marinkovic J, Vulic B, Wong ND. Risk factor indicators in offspring of patients with premature coronary heart disease in Banja Luka region/Republic of Srpska/ Bosnia and Herzegovina. Arch Med Sci. 2016;12:736-41.

40. Giusti B, Saracini C, Bolli P, Magi A, Martinelli I, Peyvandi F, Rasura M, Volpe M, Lotta LA, Rubattu S, Mannucci PM, Abbate R. Early-onset ischaemic stroke: analysis of 58 polymorphisms in 17 genes involved in methionine metabolism. Thromb Haemost. 2010;104:231-42.

41. Unal E, Mutlu FT, Karakukcu M. The importance of MTHFR polymorphisms in pediatric cerebral stroke. Childs Nerv Syst. 2012;28:13.

42. Boers GH. Mild hyperhomocysteinemia is an independent risk factor of arterial vascular disease. Semin Thromb Hemost. 2000;26:291-5.

43. Clarke R, Armitage J. Vitamin supplements and cardiovascular risk: review of the randomized trials of homocysteine-lowering vitamin supplements. Semin Thromb Hemost. 2000;26:341-8.

44. Arpino C, Compagnone E, Cacciatore D, Coniglio A, Castorina M, Curatolo P. MTHFR C677T and A1298C polymorphisms and cerebral stroke in two twin gestations. Childs Nerv Syst. 2011;27:665-9.

45. Willems FF, Aengevaeren WR, Boers GH, Blom HJ, Verheugt FW. Coronary endothelial function in hyperhomocysteinemia: improvement after treatment with folic acid and cobalamin in patients with coronary artery disease. J Am Coll Cardiol. 2002;40:766-72. 